\title{
Investigation of biomechanical risk factors for musculoskeletal disorders in the plasterer of Neyshabur, Iran, in 2014
}

\author{
Beheshti MH, MSc ${ }^{1}$, Mohammad zadeh F, $\mathrm{MSc}^{2}$, Aghababaei R, BSc ${ }^{3 *}$ \\ 1- Faculty Member, Dept. of Occupational Health, Faculty of Health, Gonabad University of Medical Sciences, Gonabad, \\ Iran. 2- Faculty Member, Dept. of Basic Sciences, Gonabad University of Medical Sciences, Gonabad, Iran. \\ 3- Undergraduate Student in Occupational Health, Student Research Committee, Gonabad University of Medical Sciences, \\ Gonabad, Iran.
}

\begin{abstract}
Received: November 2015, Accepted: December 2015

Background: Plasterers are at risk of musculoskeletal disorders (MSDs) due to the nature of their occupation and ergonomic factors. The purpose of this study was to evaluate the biomechanical risk factors for MSDs among plasterers.

Materials and Methods: In this descriptive study, 70 plasterers from Neyshabur, Iran, were studied in 2014. The Nordic Musculoskeletal Questionnaire (NMQ) was used to determine the prevalence of MSDs and the ergonomic posture of plasterers was assessed based on the Ovako Working Posture Assessment System (OWAS). The collected data were analyzed using SPSS software.

Results: According to the results of the present study, $61.7 \%$ of plasterers had experienced back pain in the past 12 months and $44.1 \%$ of individuals in the last 7 days. In addition, in the last 12 months, $58.6 \%$ of individuals had experienced pain in the knee and $44.3 \%$ had experienced pain in the neck. Postural evaluation results showed that $55.8 \%$ of working postures need to be improved. Moreover, $6.1 \%$ of these postures have a very high level of risk, and plasterers are not authorized to work in these circumstances. Of these postures, $23 \%$ should be corrected immediately and as soon as possible and $26.7 \%$ should be corrected in the near future.

Conclusions: Results indicate that the majority of plasterers suffered from MSDs especially in the upper body and upper limbs. Thus, further studies are necessary to improve plasterers' ergonomic statues.
\end{abstract}

Keywords: Musculoskeletal Diseases, Risk Factors, Biomechanical

\section{Introduction}

Musculoskeletal disorders (MSDs) are any injuries to the musculoskeletal and nervous systems that disrupt the function of each of them (1) and a wide range of acute and inflammatory conditions that influence the muscles, tendons, ligaments, joints, nerves, and blood vessels $(2,3)$. These disorders are one of the biggest problems in the workplace and a major cause of disability in countries (4) and impose a substantial economic burden upon them (5). Several risk factors are involved in causing this disorder. Numerous studies have confirmed that MSDs are more common among workers than other individuals. The majority of risk factors for MSDs are caused by occupational activity. The most important occupational factors are work environment, manual labor, lifting heavy objects, repetitive work, and heavy work (6). Reportedly, about $40 \%$ of compensation costs associated with work is related to MSDs (7).

\footnotetext{
Corresponding author: Reza Aghababaei, Student Research Committee, Gonabad University of Medical Sciences, Gonabad, Iran.

Email: r.aghababaee@yahoo.com
} 
Awkward postures and repetitive movements are important risk factors in the development of MSDs. In Iran, although reliable data is not available, the study conducted by Rahimian et al. about ergonomic risk assessment of MSDs in welders in 2014 showed that the prevalence of MSDs is the highest in the back, trunk, and knees, respectively. Results of assessment through the Quick Exposure Check (QEC) showed that scores in $14.1 \%$ of risks of disorders is high and very high (8). Favorable and unfavorable posture, duration of holding a load, and static or dynamic work, alone or in combination, play a role in the increase in the rate of these disorders (9). According to available statistics, the share of MSDs among occupational diseases In Finland was $31 \%$ and in the United States of America was 44\% (10). The study by Eidy Zadeh et al. showed that the prevalence of MSDs was high among rice harvesters (11).

In our country, a very limited number of researches have been conducted on MSDs and its direct and indirect consequences. Construction workers are at risk of workrelated MSDs. In construction workers, intense physical effort with factors such as transportation of building materials, use of tools and machinery, poor working conditions, repeated use of different body parts, vibration, and standing for a long duration of time are sources of workload. Physical workload is recognized as the cause of musculoskeletal injuries in construction workers. Construction activities are non-repetitive tasks and are very dangerous in terms ergonomics. Among the different jobs in the building industry, plasterers may be more at risk of MSDs due to the static nature of their occupation. In fact, because of the higher work speed and work at higher than shoulder levels in plastering, workers in this occupation may be exposed to more risk factors of MSDs than other individuals. The assessment of ergonomic risks caused by body unsuitable conditions can help to predict the likelihood of MSDs (12). One way to assess body condition during work is the Ovako Working Posture Assessment
System (OWAS) that is widely used in various industries (13). This method was established based on a simple and systematic classification of working conditions that are associated with the observation of duties (14). In most studies in various industries, this method has achieved a validity of over $90 \%$ (8). Due to the limited number of ergonomic studies in relation to plasterers and the rapid growth of this career in Iran, this study seemed necessary. The aim of this research was to use OWAS method to study risk factors for MSDs in plasterers and make recommendations to improve the situation of these workers.

\section{Materials and Methods}

This descriptive study was conducted on 70 plasterers in the city of Neyshabur, Iran, in 2014. The participants were randomly selected and examined. Sample size was calculated using the formula.

$$
\begin{gathered}
\text { Eq.1 } \\
\mathrm{n}_{0}=\frac{z_{1-\frac{\alpha}{2}}^{2} \mathrm{pq}}{\mathrm{d}^{2}} \\
\frac{n_{0} * N}{n_{0}+(N-1)}
\end{gathered} \quad n=
$$

The inclusion criteria consisted of lack of any MSDs and willingness to participate in the project. In this study, the Nordic Musculoskeletal Questionnaire (NMQ) was used to determine the prevalence of MSDs in different body organs of plasterers. The NMQ is used to record MSDs in 9 areas of the body including the neck, shoulders, upper back, lower back (lumbar), elbow, wrist and hand, thighs, knees, and ankles and feet.

An introduction letter was obtained from the Gonabad University of Medical Sciences, Iran, to offer the participants. Then, the NMQ was distributed among the subjects. They were assured that participation in this study is voluntary and the collected information will remain anonymous and confidential. OWAS was used for work posture assessment as one of the risk factors for MSDs. In this study, to determine working postures, the individual was photographed once every 30 seconds for 
30 minutes, and then, each photographed posture was analyzed using OWAS (12). Some of the most common postures of plasterers are shown in the following figure 1.
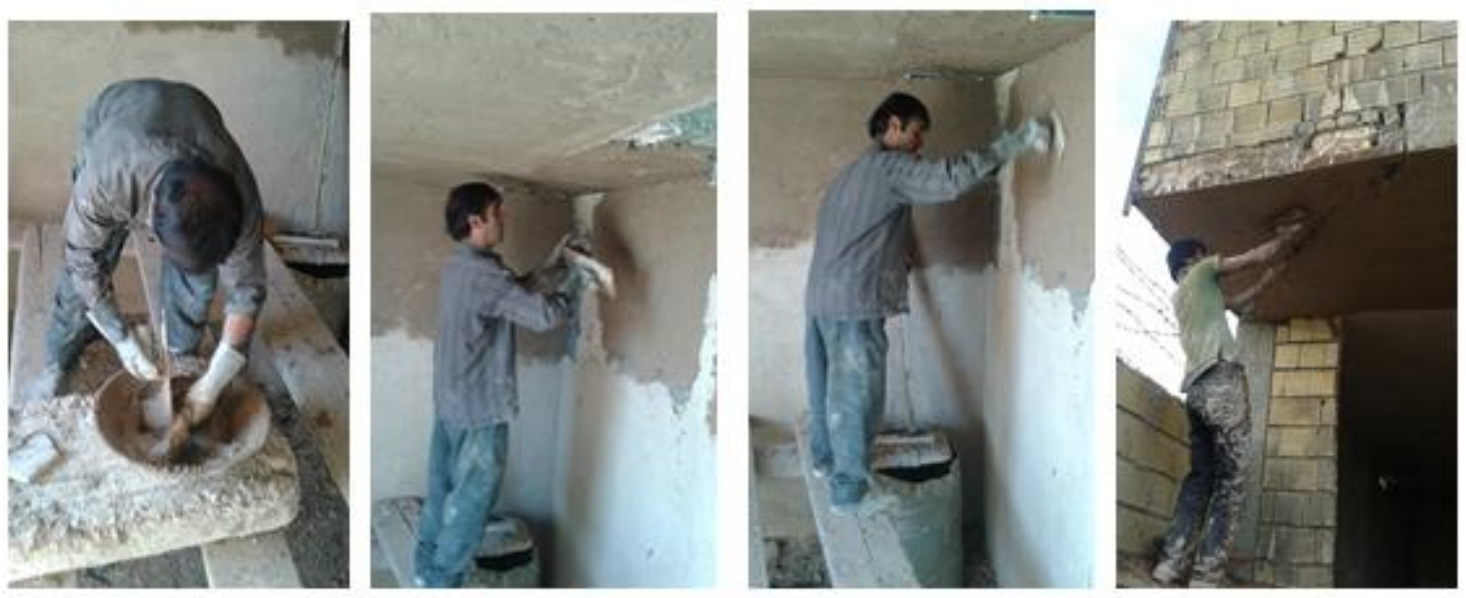

Figure 1: Some of the most common postures of plasterers

Based on OWAS, each posture was determined by a four-digit code that is applied to determine the postures of the trunk, arms, and legs and the force applied. Coding method of postures is presented below.

Trunk (spine): The score of the spine based on posture is as follows:

a. Spine stretched and straight: worker's trunk or backbone bending less than 20 degrees to the front or side and rotation of less than 20 degrees (Score 1)

b. Spine curved: the trunk is bent more than 20 degrees forwards or backwards (Score 2)

c. Body spinning: back rotated 20 degrees or more or bent to the side (Score 3)

d. Trunk spinning and curved: the trunk is bent and twisted at the same time (Score 4)

Arm: The score of the arm based on posture is as follows:

a. Both arms are lower than shoulder height (Score 1)

b. One arm is at shoulder height or above (Score 2)

c. Both arms are at shoulder height or higher than shoulder height (Score 3)
Feet: The score of the feet based on posture is as follows:

a. Sitting: body weight is transferred onto buttocks and legs are at lower height than buttocks (Score 1)

b. Standing with straight feet: body weight is tolerated by two straight feet, the knee joint angle is more than 150 degrees (Score 2)

c. Standing with a straight leg: one leg straight and the body weight placed entirely on it, in this mode the knee joint angle is more than 150 degrees (Score 3)

d. Standing on bent knees: in this posture, body weight is placed on both legs and both knees and the knee angle is about 150 or less (Score 4)

e. Standing on one bent knee: in this position, body weight is placed onto one leg and bent knee, The knee angle is 150 degrees or less (Score 5)

f. Kneeling on one or both knees: in this posture, the individual is kneeling on one or both knees (Score 6)

g. Walking or moving: in this posture, the individual is walking or moving in the workshop environment (Score 7) 
Weight or power requirements: The score of weight or required force as the fourth digit in the OWAS codes is as follows:

a. The force required is less than $10 \mathrm{Kg}$ (Score 1)

b. The force required is between $10 \mathrm{Kg}$ and $20 \mathrm{Kg}$ (Score 2)

c. The force required is more than $20 \mathrm{Kg}$ (Score 3)

Determine the priority level of encoded postures in OWAS method: After determining the score for each participant and determining the 4 digit codes for each posture, the priority action level was determined based on the combination of posture scores in OWAS method (12).

Assessment of Coded postures in OWAS method: In this study, based on the final score obtained from the captured images and the OWAS method, priority action level was determined (12). Data were analyzed using Spearman's correlation coefficient, t-test, and multiple regressions in SPSS (version 17, SPSS Inc., Chicago, IL, USA).

Table 1: Demographic characteristics of the participants

\begin{tabular}{cccc}
\hline Variable & Mean \pm SD & Maximum & Minimum \\
\hline Job experience & $14.16 \pm 10.58$ & 47 & 1 \\
\hline Age & $31.70 \pm 9.31$ & 57 & 20 \\
\hline Weight & $70.19 \pm 13.61$ & 95 & 50 \\
\hline Stature & $173.97 \pm 7.46$ & 190 & 160
\end{tabular}

\section{Results}

In this study, 70 plasterers were evaluated. Demographic characteristics of workers are presented in table 1 . The prevalence of musculoskeletal symptoms in various body organs in examined plasterers over the past year based on NMQ is presented in table 2 . According to the study results, the highest prevalence of disorders in the previous 12 months was reported in lumbar $(67.1 \%)$, knees $(58.6 \%)$, and neck $(44.3 \%)$.

Table 2: The prevalence of musculoskeletal disorders and disability caused by them in the past year in plasterers

\begin{tabular}{|c|c|c|c|c|}
\hline \multirow[t]{2}{*}{ Organ } & \multicolumn{2}{|c|}{$\begin{array}{l}\text { Pain and discomfort in the previous } 12 \\
\text { months }\end{array}$} & \multicolumn{2}{|c|}{$\begin{array}{l}\text { Disability in the previous } 12 \text { months due to } \\
\text { musculoskeletal problems }\end{array}$} \\
\hline & Number & Percentage & Number & Percentage \\
\hline Neck & 31 & 44.3 & 8 & 11.4 \\
\hline Both shoulders & 25 & 35.7 & 16 & 22.9 \\
\hline Right shoulder & 17 & 24.3 & 4 & 5.7 \\
\hline Left shoulder & 2 & 2.9 & 2 & 2.9 \\
\hline Both elbows & 8 & 11.4 & 7 & 10 \\
\hline Right elbow & 6 & 8.6 & 3 & 4.3 \\
\hline Both wrists & 8 & 11.4 & 9 & 12.9 \\
\hline Right wrist & 16 & 22.9 & 3 & 4.3 \\
\hline Left wrist & 3 & 4.3 & 1 & 1.4 \\
\hline Back & 26 & 37.1 & 8 & 11.4 \\
\hline Reins & 47 & 67.1 & 26 & 37.1 \\
\hline Hips & 11 & 15.7 & 5 & 7.1 \\
\hline Knees & 41 & 58.6 & 13 & 18.6 \\
\hline Ankles & 16 & 22.9 & 7 & 10 \\
\hline
\end{tabular}


Table 3: The prevalence of musculoskeletal disorders and disability caused by them in the previous 7 days among plasterers

\begin{tabular}{lcc}
\hline \multirow{2}{*}{ Organ } & Pain and discomfort in the previous 7 days \\
\cline { 2 - 3 } & Number & Percentage \\
\hline Neck & 15 & 21.4 \\
\hline Both shoulders & 19 & 27.1 \\
\hline Right shoulder & 12 & 17.1 \\
\hline Left shoulder & 3 & 4.3 \\
\hline Both elbows & 3 & 4.3 \\
\hline Right elbow & 6 & 8.6 \\
\hline Both wrists & 8 & 11.4 \\
\hline Right wrist & 10 & 14.3 \\
\hline Left wrist & 3 & 4.3 \\
\hline Back & 14 & 20 \\
\hline Reins & 31 & 44.3 \\
\hline Hips & 9 & 12.9 \\
\hline Knees & 21 & 30 \\
\hline Ankles & 7 & 10 \\
\hline
\end{tabular}

According to the results presented in table 2, 25 participants felt discomfort in both shoulders, 17 in the right shoulder, and 2 in the left shoulder. Moreover, 16 patients had experienced pain in the wrist and right arm, while only 3 had felt discomfort in wrist and left hand. In addition, a significant number of plasterers had experienced MSDs in upper extremities such as hips, knees, and ankles (respectively, 11, 41, and 16). The prevalence symptoms of MSDs and disability caused by them in the previous 7 days among plasterers are shown in table 3 .

Table 4: Causes of musculoskeletal disorders and absenteeism from work due to these disorders in plasterers

\begin{tabular}{|c|c|c|c|c|c|}
\hline \multirow[t]{2}{*}{ Organ } & \multicolumn{2}{|c|}{$\begin{array}{l}\text { Absence from work due to } \\
\text { musculoskeletal disorders }\end{array}$} & \multicolumn{3}{|c|}{ Causes of disorders } \\
\hline & No & Yes & workplace & Sports & Accident \\
\hline Neck & 10 & 24 & 34 & & \\
\hline Shoulder & 14 & 23 & 41 & & \\
\hline Wrist and hand & 6 & 22 & 25 & & 3 \\
\hline Reins & 9 & 31 & 41 & 3 & \\
\hline
\end{tabular}

Results presented in table 3 shows that, during the last 7 days of the study, $44.3 \%$ of the participants had experienced back pain that was the largest value between the 9 body parts examined in this study. In addition, 30 individuals had experienced knee pain and $27.1 \%$ had experienced shoulder pain. The results of this study showed that most plasterers believed that symptoms of MSDs are the result of their work environment. The results regarding impaired factor of MSDs and absenteeism from work as a result of these disorders are presented in table 4.

Table 5: Plasterers' posture assessment results based on OWAS

\begin{tabular}{lc}
\hline \multicolumn{1}{c}{ Type score } & Percentage \\
\hline 1. Does not require reform & 44.2 \\
\hline 2. Should be corrected in the near future & 26.7 \\
\hline 3. Should be corrected as soon as possible & 23 \\
\hline 4. Urgently needs to be corrected & 6.1 \\
\hline OWAS: Ovako Working Posture Assessment System &
\end{tabular}




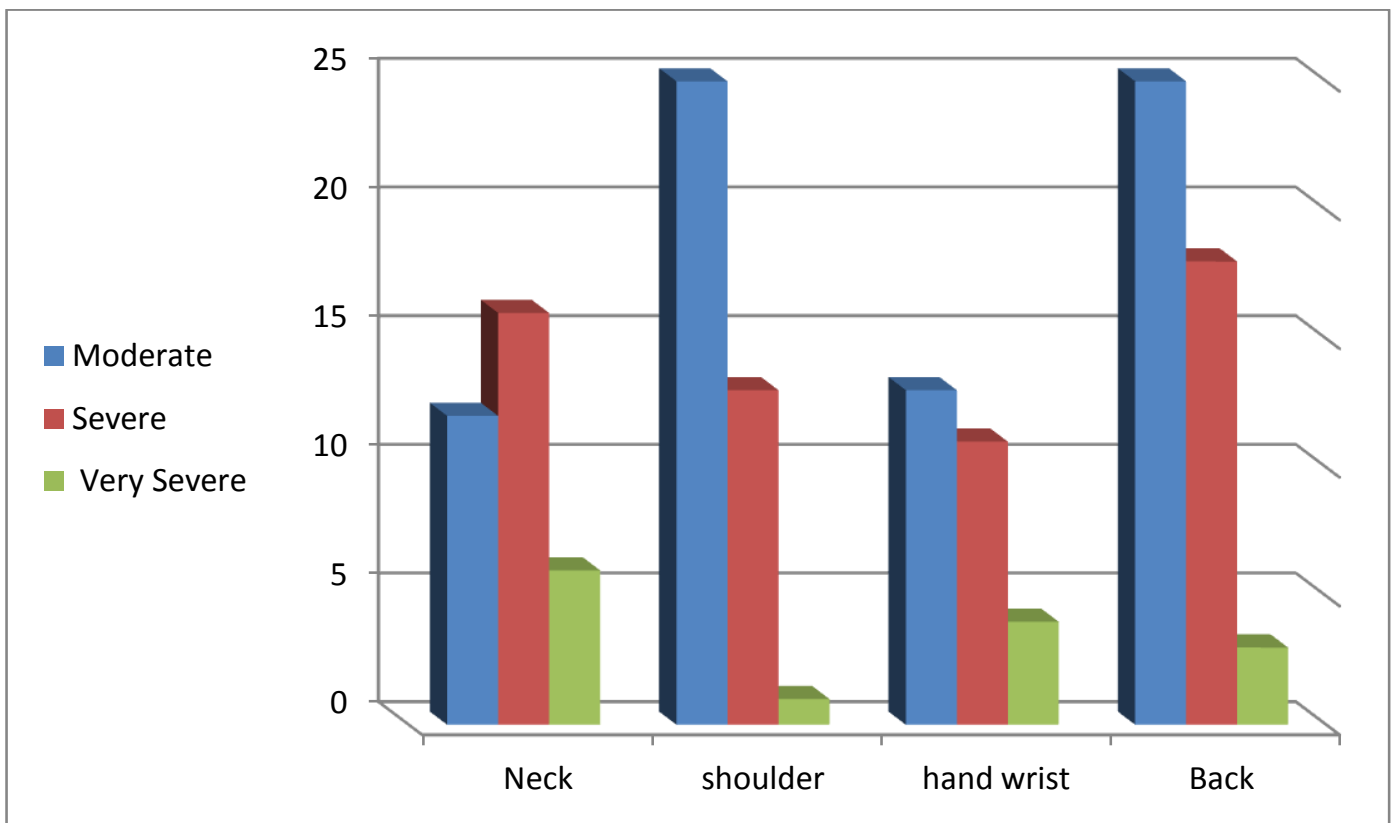

Figure 2: Pain severity of musculoskeletal disorders (MSDs) in plasterers based on the Nordic Musculoskeletal Questionnaire

The results regarding pain intensity associated with MSDs among plasterers are illustrated in figure 2. The intensity of low back and neck pain, and shoulder and wrist pain were the greatest, respectively.

Assessment results of plasterers' postures based on OWAS are demonstrated in figure 3 and table 5. According to the study results,
$55.8 \%$ of working postures in plasterers require reform, and $26.7 \%$ of them must be modified in the near future. In addition, $23 \%$ of postures should be modified quickly and as soon as possible. Moreover, $6.1 \%$ of postures have a very high level of risk and plasterers should never work in these situations.

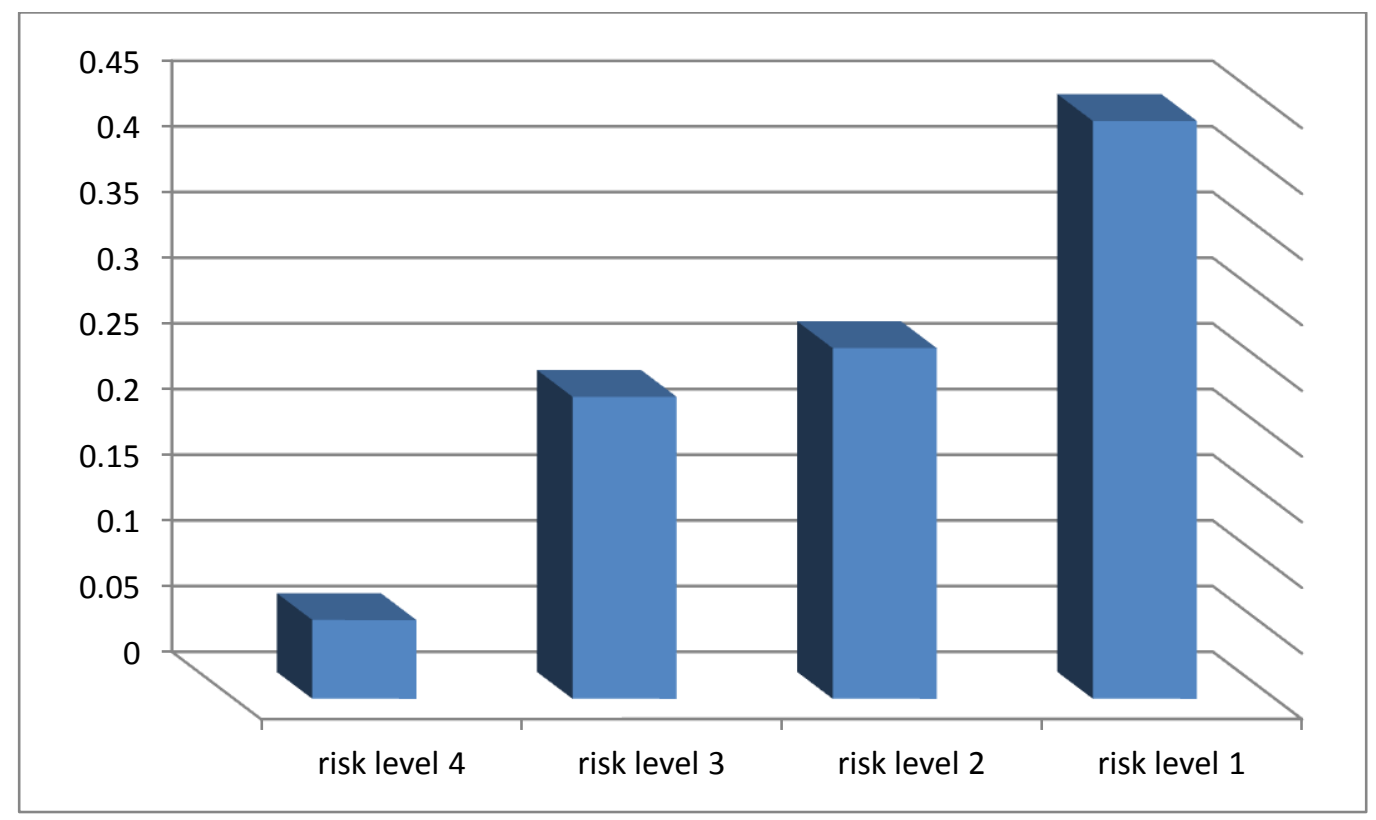

Figure 3: Priority of corrective actions in working postures of plasterers 


\section{Discussion}

In this study, data obtained from the NMQ showed that most musculoskeletal discomfort in plasterers in the previous year have been observed, respectively, in the lumbar (67.1\%), knee $(58.6 \%)$, and neck (44.3\%). Furthermore, the greatest discomfort in 7 days of the research period was in the lumbar (44.3\%), knee $(30 \%)$, and shoulder (27.1\%). Results of ergonomic working posture assessment in plasterers based on OWAS showed that $55.8 \%$ of working postures need to be corrected, $6.1 \%$ of which had a very high level of risk and plasterers are not allowed to work in these situations. In addition, $23 \%$ of postures should be corrected as soon as possible and $26.7 \%$ of postures should be corrected in the near future. Numerous studies have shown that improper body posture is the cause of MSDs and reduced labor productivity. Based on the results of this study, inappropriate posture and repetitive acts are significant risk factors that play a role in MSDs in plasterers. Unfortunately, ergonomics studies in the field of plasterers are very limited. Comparison of the results with that of other studies have shown that among MSDs, back pain is far more prevalent. The study by Chubineh et al. showed that $60.6 \%$ of nurses have experienced back pain and $51.1 \%$ neck pain (15). In addition, in the study by Mehrdad et al., the prevalence of low back pain and neck pain in nurses were $73.2 \%$ and $48.76 \%$, respectively (16).

Moreover, in the study by Dehghani et al. on welders, the greatest distress was reported in lumbar $(52 \%)$, knee (48\%), and back (38\%), respectively (17). The study by Rowshani et al. on the effect of postures on MSDs in the work place showed that based on the Rapid Upper Limb Assessment (RULA) scoring method, for the right hand, $46 \%$ of cases were at grade $2,52 \%$ of cases were at grade 3 , and only $2 \%$ of cases were at grade 4 . Regarding the left hand, $44 \%$ of cases were at grade 2 , $54 \%$ of cases were at grade 3 , and $2 \%$ of cases were at grade 2 (18). The scores obtained in this study were slightly lower than those of the present study, which may be due to the difference in the type of construction activity assessed. The static nature of plastering may be the cause of increase in the percentage of disorders.

Moreover, in the study by Hokmabadi et al. on ergonomic assessment of MSD risk factors in construction workers, trunk and legs status assessment using the Posture, Activity, Tools, and Handling (PATH) Method showed that activities in the neutral state make up about $50 \%$ of the workers' time. In most occupations, about $80 \%$ of laborers work in a neutral position and about $51 \%$ of laborers do not perform weight-bearing activities (19). By analyzing the scores of body posture assessment through OWAS in plasterers the undermentioned reasons can be presented to justify these results:

1. Dangerous body posture when performing high frequency and rapid activity

2. Lack of use of ergonomic principles at work

3. The simultaneous use of a board with fixed height by individuals with different heights, that in such conditions unfavorable board height inflicts great pressure on these people.

4. The performance of plastering in closed environments with a high relative humidity, due to plastering, and the speed of work in this field, excessive sweating, and cold body, especially during their breaks

5. Lack of adequate rest during work

It may be possible to provide a condition in which plasterers can more easily adjust surface height by using metal scaffolding, and improve their working conditions through using modern methods of construction and prefabricated components. The results of the current study and studies conducted inside and outside the country have illustrated that construction workers, particularly plasterers, are exposed to MSDs caused by ergonomic factors. Unfortunately, the emphasis of occupational health authorities on ergonomics 
and industrial workers has led to the neglecting of this important sector of the workforce and studies in this field are very limited. Hence, further investigations in this regard, and efforts to implement ergonomic principles and apply standard equipment and appropriate changes in the work process are recommended. It is necessary to convert this occupation into a more efficient and optimized occupation in which the least damage is caused to the musculoskeletal system, especially in the lower back, neck, and knee. This will result in the prevention of a considerable amount of expenses, musculoskeletal injuries, and work-related absences.

\section{Conclusion}

It can be concluded that most of the risk factors evaluated were at an undesirable risk level. The results showed that the correction of work postures and work process is essential in order to prevent disorders in the back, knee, neck, and shoulders. Instructing plasterers on ergonomics principles and compliance with these principles, such as increasing the height of the container from the ground using a foundation for plastering container, arranging a work-rest cycle, using appropriate scaffolding and adjusting the length of the scaffolding board from the ceiling so that to prevent from bending the lumbar backward and tilting the neck to one side may be effective in reducing disorders. Furthermore, improving the ergonomic knowledge of plasterers by training and introduction of improper postures and implementing ergonomic principles can lead to change in working conditions, improvement of user safety, reduction of medical costs, and increasing of productivity and efficiency. Failure to assess the right and left sides of the body separately through OWAS method, lack of evaluation of the neck, elbow, and wrist, as well as other risk factors that effect the development of MSDs such as repetition and duration of consecutive posture are the limitations of this study.

\section{Acknowledgement}

This study has been registered as a research project in the Student Research Committee of Gonabad University of Medical Sciences. The authors would like to thank Gonabad University of Medical Sciences.

Conflict of interests: None declared.

\section{References}

1. Malekpour F, Mohammadian Y, Moharampour A, Malekpour A. Assessment impact of musculoskeletal disorders and physical activity on quality of life automobile factory workers. Journal of Ergonomics 2014; 2(1):19-26

2. Al-Eisa E, Buragadda S, Shaheen AA, Ibrahim A, Melam GR. Work related musculoskeletal disorders: causes, prevalence and response among egyptian and saudi physical therapists. Middle East J Sci Res 2012; 12(4):523-9.

3. Stahl S, Vida D, Meisner C, Lotter O, Rothenberger J, Schaller HE, et al. Systematic review and meta-analysis on the work-related cause of de Quervain tenosynovitis: a critical appraisal of its recognition as an occupational disease. Plast Reconstr Surg 2013; 132(6):1479-91.

4. Habibi E, Haghi A, Habibi P, Hassanzadeh A. Risk Identification with a Particular Tool: Risk Assessment and Management of Repetitive Movements. Journal of Health System Research 2013; 8(6):972-80.

5. Koehoorn M, Cole DC, Hertzman C, Lee H. Health care use associated with work-related musculoskeletal disorders among hospital workers. J Occup Rehabil 2006; 16(3):41124

6. Smith DR, Wei N, Kang L, Wang RS. Musculoskeletal disorders among professional nurses in mainland China. J Prof Nurs 2004; 20(6):390-5.

7. Palmer KT, Harris EC, Linaker C, Cooper C, Coggon D. Optimising case definitions of upper limb disorder for aetiological research and prevention: a review. Occup Environ Med 2012; 69(1):71-8.

8. Tayefe Rahimian J, Choobineh A, Dehghan N, Tayefe Rahimian R, Kolahi H, Abbasi M, et al. Ergonomic evaluation of exposure to musculoskeletal disorders risk factors in welders. Journal of Ergonomics 2014; 1(3):18-26.

9. Abdoli-Eramaki M. Body mechanics and workstation design principles (Ergonomics). 
Tehran: Omid Majd Publishing Co.; 2000. P.253-7.

10. Mattila M, Vilkki M. OWAS method. In: Karwowski W, Marras WS, ed. The occupational ergonomics handbook. Boca Raton FA, USA: CRC Press LLC; 1999. P.447-59.

11. Ranjbar F, Etmadinezhad S. Ergonomic evaluation in rice mills workers in Sari in 2014. Journal of Health Research in Community $2015 ; 1(1): 42-8$.

12. Chubineh AR. Posture assessment methods in occupational ergonomics. $3^{\text {rd }}$ ed. Tehran: Fanavaran; 2010.

13. Etemadinezhad S, Ranjbar F, Gorji M. Posture analysis by OWAS method and prevalence of musculoskeletal disorders using nordic questionnaire among workers of sourak tobacco factory in 2013. Iranian Journal of Health Sciences 2013; 1(2):89-94.

14. Louhevaara V, Suurnakki T. OWAS a method for the evaluation of postural load during work. Helsinki, Finland: Instatute of Occupational Health, Center for Occupational Safety; 1992. P.23.

15. Choobineh A, Movahed M, Tabatabaie SH,
Kumashiro M. Perceived demands and musculoskeletal disorders in operating room nurses of Shiraz city hospitals. Ind Health 2010; 48(1):74-84.

16. Mehrdad R, Dennerlein JT, Haghighat M, Aminian O. Association between psychosocial factors and musculoskeletal symptoms among Iranian nurses. Am J Ind Med 2010; 53(10): 1032-9.

17. Soltani R, Dehghani Y, Sadeghi Naieny H, Falahaty M, Zokai M. The welders posture assessment by OWAS technique. Occupational Medicine Quarterly Journal 2011; 3(1):34-9.

18. Rowshani Z, Mortazavi SB, Khavanin A, Motamedzade M, Hajizade E, Mohseni M. The effect of postures on musculoskeletal disorders in work places. Journal of Kermanshah University of Medical Sciences 2012; 16(5):367-74.

19. Hokmabadi RA, Fallah H. Ergonomic assessment of musculoskeletal disorders risk factors in construction workers by PATH method. Journal of North Khorasan University of Medical Sciences 2013; 5(1):62. 